\title{
A idealización no exilio: construír a identidade, reconstruír a vida
}

\author{
Idealization and Exile: Constructing Identity, Reconstructing Life
}

\author{
María Jesús PiñeIro Domínguez \\ Universidad Complutense de Madrid \\ mariajpi@ucm.es \\ [recibido 30/10/2014, aceptado 27/01/2015]
}

\section{RESUMO}

A partir de varios exemplos da narrativa peninsular de posguerra, analizamos os efectos dun proceso levado a cabo por moitos exiliados para sobrevivir á migración forzada: a transformación da realidade hostil nun ideal imaxinario. A idealización disfraza os sentimentos e facilita a construción dunha nova identidade, así como a reconstrución dunha vida truncada pola guerra. Pero tamén é unha fuxida na que os exiliados non poden atopar refuxio.

PALABRAS CHAVE: Exilio, idealización, literatura, identidade, migracións.

\section{RESUMEN}

A partir de varios ejemplos de la narrativa peninsular de posguerra, analizamos los efectos de un proceso llevado a cabo por muchos exiliados para sobrevivir a la migración forzada: la transformación de la realidad hostil en un ideal imaginario. La idealización disfraza los sentimientos y facilita la construcción de una nueva identidad, así como la reconstrucción de una vida truncada por la guerra. Pero también es una huida en la que los exiliados no pueden encontrar refugio.

PALABRAS CLAVE: Exilio, idealización, literatura, identidad, migraciones.

\section{ABSTRACT}

Starting from several examples of the peninsular narrative from the postwar period, we will analyze the effects of a process carried out by many exiles to survive the forced migration: the transformation of hostile realities into imaginary ideals. Idealization disguises feelings, and it contributes to the construction of a new identity and to the reconstruction of a life dashed by war. But it also represents an escape where the exiles cannot find refuge.

KEY WORDS: Exile, idealization, literature, identity, migrations.

PiñeIro Domínguez, Ma J. (2015): “A idealización no exilio: construír a identidade, reconstruír a vida”, Madrygal (Madr.), 18, Núm. Especial: 299-308.

SUMARIO: 1. Introdución. 2. A negociación da identidade. 3. A idealización na narrativa do exilio. 4. Conclusións.

5. Referencias bibliográficas. 


\section{INTRODUCIÓN}

O exilio provoca sentimentos contraditorios e reaccións inesperadas nas persoas que o sofren. Os exiliados atópanse ante unha circunstancia extraordinaria e mostran actitudes que pasan pola inadaptación á nova etapa, a frustración, a depresión, a culpabilidade, o medo ao esquecemento ou a sensación de abandono, entre outras. Pero tamén hai quen ve no exilio unha oportunidade de reelaboración do periplo vital mediante o fortalecemento da identidade, a procura de novas oportunidades, o renacemento persoal e profesional ou a exploración e explotación dos recursos propios, por citar algúns exemplos.

$\mathrm{Na}$ actitude finalmente adoptada, e na resolución ou non dos conflitos internos, inflúe enormemente un proceso coñecido como idealización, que consiste na invención dunha realidade paralela, imaxinaria, coa intención de ocultar o sufrimento non exteriorizado. Este recurso, baseado na proxección dun ideal e na negación da realidade, é moi utilizado en situacións de incerteza e angustia, como a do exilio; e por iso, os exiliados botan man del para intentar adaptarse ao desterro, aínda que con resultados desiguais, como reflicten moitos escritores a través das súas obras e dos seus personaxes.

Precisamente, na narrativa do exilio achamos as mostras máis significativas do uso da idealización. $\mathrm{Na}$ análise que propoñemos, que recolle textos procedentes dalgunhas obras da literatura peninsular de posguerra, partiremos da definición de exilio que ofrece o dicionario da Real Academia Española, que fai referencia a unha expatriación ou separación da terra, principalmente por motivos políticos. Pero tamén aplicaremos unha perspectiva máis psicolóxica ou sociolóxica, e en todo caso interdisciplinaria, que nos permita achegarnos ao exilio dunha forma non tan descritiva, senón introspectiva.

Así, tendo en conta esta visión máis integradora, que non limita o estudo ao ámbito político, introduciremos un concepto clave na relación entre idealización e exilio: a ruptura. Porque a ruptura é a que fomenta a proxección irreal e ideal desa vida e máis desa identidade que quedaron truncadas pola guerra. Pero tamén é a que da pé ao proceso de reconstrución das dúas a través da reelaboración da perda.

A continuación, anotaremos as características principais da idealización e mostraremos o seu reflexo nalgunhas obras da narrativa peninsular de posguerra. Posteriormente, sacaremos algunhas conclusións sobre os efectos deste mecanismo de supervivencia, que crea nos personaxes a falsa ilusión de ter resoltas ou esquecidas as circunstancias que deron lugar á súa situación actual.

\section{A NEGOCIACIÓN DA IDENTIDADE}

O obxectivo fundamental da idealización é facilitar a reconstrución da identidade rota. Para iso, é necesario que o exiliado adopte unha actitude adormecida, mesmo anestesiada, que lle permita converter a realidade hostil nun ideal imaxinario, porque doutra forma non sería capaz de soportar a perda da súa vida anterior. Non podería superar a ruptura. Nace así a negociación da identidade propia.

O problema é que esta suposta reconstrución está baseada nunha falsa percepción da realidade, ou mellor dito, na negación mesma do que aconteceu. Fórmase unha visión dos feitos que non é real nin sólida e, por tanto, está condenada a fracasar, como veremos nos exemplos que se citarán despois.

Que se idealiza?

Idealízanse os lugares, como a terra de acollida e a terra de orixe. Os espazos aparecen difusos entre os recordos e as expectativas dos exiliados, e así, a dor pola terra perdida convértese en agarimo e nostalxia; e a incerteza pola adaptación ao novo destino diminúe ante o convencemento de vivir un desterro temporal.

En relación estreita cos lugares, idealízase o tempo: o pasado, o presente e o futuro. $\mathrm{O}$ exiliado garda unha imaxe inmutable do pasado e máis da súa terra. Nin o tempo nin os espazos parecen evolucionar na súa memoria. A pesar de terse producido unha expulsión do presente e do futuro do país de orixe (Guillén 
1995: 141$)^{1}$, para o exiliado o pasado representa un alento; e o futuro, a esperanza do cambio que ha de vir. Pensar no pasado e no futuro forma parte do seu día a día. O presente, simplemente, non existe.

Tamén se idealiza a xente: os familiares que quedaron atrás, os veciños e amigos que non quixeron ou non puideron marchar, as novas amizades no país de destino... O exiliado ve nestas persoas aos colaboradores necesarios para a recuperación dos dereitos perdidos e ansía o seu recoñecemento polo sacrificio realizado. Pero eles non comparten a mesma visión e agochan resentimentos, desconfianza, medos e outros sentimentos dolorosos que non se axustan aos ideais do emigrado.

Idealízase a identidade propia, especialmente cando aparece vinculada á idea da persoa "feita a si mesma", que fixo as Américas e se enriqueceu deixando atrás unha vida de miseria e conformismo. Mais sabemos que en moitos casos trátase dunha descrición exaxerada dos feitos, xa que o emigrado acada o éxito despois de grandes esforzos, renuncias e sufrimento.

Ás veces, idealízase o propio exilio. Coa intención de evitar xuízos políticos externos, e mesmo xuízos internos, o exiliado acóllese ao chamado retiro voluntario do intelectual ${ }^{2}$, eliminando o carácter forzado do desterro e transmitindo a idea de que abandonou o país por decisión propia.

\section{E por que se idealiza?}

Por unha banda, idealízase para reconstruír unha identidade e unha vida rotas pola guerra e máis pola ditadura. Ante a dureza dos feitos, recórrese ao ideal, do que xorden novos mundos, novas historias nas que crer e, sobre todo, a sensación de non ter todo perdido.
Por outro lado, e en relación co punto anterior, a idealización permite ocultar sentimentos difíciles de xestionar, como a dor, o medo, a culpabilidade, o abandono, a frustración ou as críticas, entre outros.

Tamén se idealiza para alimentar a esperanza dun futuro mellor, dun mundo máis xusto, dun cambio que ha de vir. Nese contexto, a esperanza emerxe como consecuencia da negación da realidade, que demanda a creación dunha vía de escape que achegue algo de luz á escuridade.

Idealízase para acadar xustiza poética, que outorga finais felices aos bos e castiga a maldade. Búscase unha compensación pola inxustiza do sufrimento vivido; unha recompensa baseada na convicción do merecemento de algo bo.

A idealización é útil para fuxir, tanto da situación externa (a guerra, a represión) como da interna (os conflitos, os traumas), que son as que quebran a integridade do exiliado e máis da sociedade. É dicir, idealízase para sobrevivir á ruptura.

A continuación presentamos algúns textos da literatura do exilio nos que os personaxes recorren á idealización para enfrontar esa realidade da que escaparan, a mesma que causou a ruptura traumática da súa vida. Analizaremos as circunstancias que os levaron a proxectar eses mundos paralelos e as consecuencias desa decisión.

\section{A IDEALIZACIÓN NA NARRATIVA DO EXILIO}

A literatura é unha das principais fontes testemuñais do exilio. Isto é debido a que, por unha banda, moitos escritores viviron os feitos

\footnotetext{
${ }^{1}$ Claudio Guillén (1995: 141) introduce o concepto de "destempo": "El destierro conduce a ese "destiempo' (...), a ese décalage o desfase en los ritmos históricos de desenvolvimiento que habrá significado, para muchos, el peor de los castigos: la expulsión del presente; y por lo tanto del futuro -lingüístico, cultural, político- del país de origen".

${ }^{2}$ Tamén Claudio Guillén (1995: 54, 60) fai esta distinción entre exilio político e filosófico e lembra a existencia de desterros voluntarios, como o de Séneca e os dalgúns intelectuais chineses. E apunta que, para os estoicos, o exilio era unha oportunidade.
} 
que están a narrar e os transmiten. Este é o caso da novela testemuñal ou da novela autobiográfica, pero tamén hai moitas obras de ficción que, sen seren deste tipo, reflicten a pegada dos acontecementos históricos no autor.

Por outra banda, o exilio é un tema que favorece a creatividade literaria porque pode explorarse desde moitas perspectivas (histórica, política, sociolóxica...). Ademais, considérase que a novela é un dos medios máis adecuados para a reflexión, xa que obriga ao lector a participar con hipóteses, argumentos e críticas, entre outros, e funciona como un instrumento pedagóxico capaz de transmitir feitos históricos (Thompson 2009: 11).

Na primeira das obras que propoñemos, a idealización proxéctase cara ao exterior, cara ao país de acollida. A fuxida é unha novela de Xosé Manuel Martínez Oca publicada en 1980. Ofrece unha testemuña da emigración europea nos anos 70 e trata da estancia en Suíza dun rapaz chamado Faustino durante os últimos anos do franquismo. Faustino, apresado varias veces e acusado de comunista, renega da política e do país, e decide que único que quere é fuxir. Así se manifesta no limiar: "Fuxir, esa era pra min a única solución naquel intre. A solución que todos os meus devanceiros dende que acorda na memoria dos vellos tomaran sempre diante da hostilidade da terra e da xente arredor seu" (1983: 27).

Faustino aproveita a invitación de Xaquín, un amigo da infancia a quen considera o seu salvador, e marcha á súa casa de Xenebra sen pensalo moito. Aínda que o amigo trata de advertilo e dille: "Pénsao un pouco, rapás (...). Non tomes decisións apuradas. Descansa un tempiño e deixa acougar as cousas. Eu seiche ben o que é estar fóra" (1983: 27), Faustino idealiza o seu amigo, idealiza o país e celebra esa decisión de abandonalo todo que ha de resolver o seu malestar:

Ai, Xaquín, amigo, ti si que sabes como son as cousas que sempre andan a moer por dentro de min. O Xaquín é vedoiro. O Xaquín sabe, soubo sempre o que o meu pensamento pode retellar. O Xaquín ó lonxe é coma un pai. Pai velante, anxo guardián. (1983: 28)
Da relación idílica que describe co seu "anxo guardián", o protagonista pasa á ilusión pola terra de acollida, onde vai atopar a liberdade:

(...) púxenme a pensar no paraíso que me agardaba en Suiza. O paraíso. (...) O meu amigo, Xaquín, Suiza, paraíso verde e nevado. (...) $\mathrm{O}$ amigo-pai-anxo-da-garda e non quero pensar cantas cousas mais ábreme os brazos para que vaia onda el. E eu vou marchar, na busca dese paraíso que non é outra cousa que a liberdade. (...) O paraíso, o paraíso... Non haberá paraísos, pero mañán eu, un pé diante doutro, collerei camiño pró conquerir. $\mathrm{Si}$, meus peíños, vós sodes os que acabaredes por me salvar. (1983: 28-30)

Pero ao chegar a Xenebra, comezan as decepcións. Nese "paraíso", comproba que as súas expectativas de liberdade van ir caendo na decepción. O seu amigo Xaquín élle un descoñecido polo seu carácter frívolo e despreocupado; e parece que esa amizade, idealizada na distancia, agora é difícil de levar nas distancias curtas.

Malia o desengano, Faustino insiste en conquistar o seu paraíso perdido e coñece unha rapaza da que se namora. E comeza outra vez a recrear unha película que o distraia das súas batallas internas:

E xa ningunha outra cousa me importaba no mundo mais que Ana. Nin a Terra, nin a xente, nin nada. (...) as vacilacións, as dúbidas, os medos, as fuxidas, todo se borraba por ensalmo de min, que non tiña pasado nin quería ter futuro, vivir namais nun eterno presente con Ana. E sabía, tiña a certeza de que os meus desexos se habían cumplir, porque estaba escrito que ela e mais eu nos tiñamos que atopar, tiñamos que nos conocer e teriamos que ficar xuntos pró resto do tempo que nos quedase por vivir. (1983: 132)

Ata agora, Faustino proxectou de forma irreal a súa relación con Xaquín (o pai, o anxo gardián) e máis a relación co país de acollida (o paraíso), ignorando de todo as circunstancias da súa vida en España; unha situación que continuará ao idealizar tamén á rapaza e que vén confirmar a falta de madurez do protagonista, incapaz de saír por si mesmo do seu cárcere interior. De feito, Ana, 
coa que finalmente chega a ter unha relación, convértese na súa salvadora tras a decepción que levou co amigo:

El que fora o pai velante, o auxiliador máxico, agarimo no que atopar forza a miña febleza, empezábaseme a facer unha compañía indesexada. (...) Ana, Ana, en ti está a miña salvación, ti apartarasme da dependencia do Xaquín, esa dependencia alingreira na que sempre me vin co meu amigo, e para ti terei eu o amor mais grande que un home pode ter. (1983: 142)

A capacidade deste personaxe á hora de mesturar o real e o imaxinario aínda vai máis alá cando idealiza incluso o país do que fuxiu e busca argumentos para convencer á súa moza de que vaian de visita a España cando morra o ditador. Por se Ana se negara a volver, el pensa dicirlle: "Pero a miña terra é distinta, xa verás. A miña terra non é a España que ti conoces" (1983: 179).

Eses recordos imaxinarios do pasado, xunto coa cegueira que mostra Faustino no presente, vanlle pasar factura cando é o futuro o que lle pecha as portas a calquera relación posible coa moza. Porque Ana confésalle os verdadeiros motivos que ten para permanecer en Suíza:

Escoita, Faustino (...). Díxenche que viñera hai sete anos a Suiza pra pasar unhas vacacións de vrau nun campo de traballo pra mozos, e que dende aquela ficara namorada do país. O que non che acabei de dicir foi que de quen quedei verdadeiramente namorada foi de Xaquín. (...) Por el é polo que estou nesta terra. (1983: 187)

Esta é unha revelación moi dura para Faustino, que perde o seu único punto de apoio e que marca un antes e un despois na evolución do personaxe. Así, recoñece que: "aquelas palabras ditas mainamente, cun acento monocorde, resignado, atoleáronme. Entraban polos meus ouvidos pero non era capás de interpretalas, negábame a captar a revelación que me ofrecían" (1983: 187). E nese momento esperta do seu soño, consciente da súa soidade interior. Unha soidade que todos senten e da que todos escapan:
No seu ollar vin o refrexo dunha dor, dunha perda. E a través daquel refrexo coidei chegar ó cerne dunha grande soedade. Si, Xaquín estaba soio tamén. Coma min. Coma Ana. (...) Quédate ti ahí, Xaquín, á busca do paraíso imposible nesa Xenebra de seres senlleiros, a te afogares pouco a pouco na túa soedade sin esperanzas. (1983: 193)

O despeito de Faustino revela a necesidade dun crecemento interior, dunha madurez que chega cando o protagonista decide deixar de soñar e regresar a España para cumprir coas súas obrigas: "Agora xa non che comprirá recurrir á imaxinación pró teu intento de fuxida, Faustino, díxenme aquela noite (...)" (1983: 196). Así, comprobamos que a fuxida cara ao exterior, en verdade, ocultaba unha fuxida interior, porque o personaxe estaba loitando consigo mesmo. Finalmente, comprende que a única solución para os seus conflitos consiste en enfrontar a realidade do país e asumir o seu compromiso político e social, ademais do persoal: facerse cargo da súa vida.

Cambiamos de escritor e de escenario, e citamos outra obra na que a idealización non se proxecta cara ao exterior e cara ao futuro, como en A fuxida, senón cara ao interior e cara ao pasado, durante o retorno á terra de orixe.

O exiliado e a primavera é unha novela do escritor e xornalista Manuel Veiga publicada en 2004. Trata do regreso de Alexandre Marrube á súa cidade natal para asistir ao enterro da súa nai. Despois de case 40 anos de exilio en México, o protagonista atopa unha terra e unha sociedade que non recoñece, e esta experiencia causa nel un impacto brutal.

O exiliado, tal e como nolo describe o narrador, é: "unha persoa de principios, aínda que quizais a esta altura se rexa máis polos recordos" (2004: 17). E de feito, vai ter ocasión de contrastar os seus recordos coa realidade cando chega á súa vila, onde queda impresionado polos cambios da cidade e da paisaxe:

Nos días seguintes paseou pola cidade co obxectivo mórbido de cerciorarse de que xa non recoñecería nada, nin a ninguén, e estivo a piques de logralo. $\mathrm{O}$ barrio da estación figuraba agora perfectamente unido ao que chamaban pueblo por ringleiras de casas (...) Os barrios 
campesiños de Ranverde e Carude eran agora urbanos, desapareceran os palleiros e os canastros, reducíranse as hortas e as leiras de patacas e xa non había case neles cortes de gando. (2004: 27)

Curiosamente, no fondo o protagonista é consciente de que regresa a un lugar que só existe nas súas lembranzas. Sabe do paso do tempo e das trampas da memoria, pero así e todo, non pode evitar evocar as paisaxes da súa infancia, como a do río Cabe:

O Cabe parecía o mesmo, pero xa non era o Cabe, aquel río no que os cativos se enxaboaban e bañaban cando nas casas non había nin cuarto de aseo, nin sequera auga corrente (...). Agora, grazas a unha presa, parecía máis grande, pero ao velo de preto un desilusionábase coas súas augas estantías, mortas coma nun estanque. (2004: 28)

Axiña comprobaremos que a integridade do exiliado, que parecía preparado para os cambios físicos e xeográficos, vai chocar coa actitude dunha sociedade consumista, abraiada polos agasallos propagandísticos -como a construción de presas e encoros por parte do Réxime-e absorbida polas innovacións tecnolóxicas. Un cambio social para o que el non estaba preparado, como veñen anticipar as palabras doutro dos personaxes da novela: "Agora era diferente" (2004: 29).

E malia as diferenzas, Alexandre seguirá intentando recompoñer o seu particular crebacabezas, aínda que lle é difícil encaixar as pezas. Por exemplo, a xente non é a mesma:

Co paso do tempo até lle custaba recoñecer algún trazo familiar nas caras que lle saían ao paso, aínda que, a base de observar as vivendas foi identificando por si mesmo a fillos e netos de antigos moradores, sen necesidade de preguntarlle nada á súa irmá ou ao seu cuñado. (2004: 30)

Neste reencontro coa súa terra natal, Alexandre entra en contacto cun mozo antifranquista que esperta a súa ilusión pero co que non acaba de encaixar, porque a pesar de que comparten ideoloxías, non comparten métodos. O exiliado ve no rapaz unha oportunidade para transmitir a súa experiencia e para loitar contra o esquecemento, pero el mesmo desconfía da súa percepción e pensa que quizais o idealiza:

Despois dunha vida como a miña, pensaba, un precisa saber que fica algo do sementado, unha sorte de fillo político, se vale a expresión. Mais tamén tiña medo de que a relación non discorrese por onde el desexaría, medo de que o mozo non fose como el imaxinaba e non podía selo. Ningún mozo é como anceiarían os maiores. (2004: 51)

Aquí xa se intúe o choque xeracional, que se verá incrementado pola necesidade de recoñecemento social e político de Alexandre. Efectivamente, a desilusión dese "fillo político" chega axiña, cando o rapaz se ri del despois de que o exiliado lle entregara un só exemplar dun libro censurado. $\mathrm{O}$ exiliado queda indignado:

Pero, de contado, comezou a matinar en que se cadra o mozo tirara xa a conclusión de que a grande organización de América só consistía nun grupo minúsculo de nostálxicos, imprimindo folletos no soto dun emigrado rico que os toleraba por consideralos inanes. Pensou que quizá debería darlle unha explicación mellor, mais finalmente non dixo nada. Como explicarlle todo iso? Como explicarlle a quen nada vivira? Como facerlle sentir só un chisco do que sentiran eles? Como contarlle o que significaran aqueles tempos, cando todos os da súa quinta pasaran de mozos a vellos en poucos anos, quizá só en poucos meses? Sorpréndeme un pouco a súa arrogancia, recoñeceu para os seus adentros. Ou se cadra é que eu agardaba algo máis de respecto, unha reverencia talvez. (2004: 54-55)

Os desenganos do protagonista van ser constantes: co rapaz, coa súa familia que renega del, cos veciños que o miran con desconfianza, cos que quedaron e teñen un sentimento de culpabilidade e covardía á vez... A dureza da situación faille darse conta de que no pasado non vai atopar recoñecemento ningún:

Pero logo regresas e ves que (...) até os máis duros arrombaron a memoria no faiado. Volves e non es ninguén, eu non son ninguén para ti. Que agardaba? Ser tratado coma un anxo que vén facer a súa boa acción ou como un pai que vén dar os seus consellos? Quizais. Pero os que debían ser os teus fillos non te recoñecen. Non teñen o teu carácter, non comparten nada. (2004: 109) 
Alexandre está rodeado por unha realidade que o vai destruíndo por dentro. O choque xeracional, histórico e familiar frustra as súas esperanzas de atopar un cambio social e político na comunidade. $\mathrm{O}$ exiliado busca en Galicia ese mundo perdido que deixou atrás, pero só ve unha sociedade devorada polo consumismo, pobre intelectualmente, e que esqueceu a súa historia máis recente. A súa morte pouco despois anúnciase ao final do relato. A ansiada primavera $^{3}$ que inconscientemente fora buscando xa non vai chegar para el.

Tras este reencontro-desencontro no que a idealización se proxecta en forma de retorno ao pasado, presentamos unha obra do escritor catalán Lluís Ferran de Pol, que estivo exiliado en México. Da súa experiencia no exilio xurdiu o conxunto de relatos La ciutat i el trò$p i c^{4}$, publicado en 1956, unha obra que revela a fascinación do autor polos ambientes mexicanos e tamén as consecuencias do choque de culturas.

Centrarémonos nun deses relatos, chamado "A lletra", que narra a historia dun home apoucado e sen ambicións que é abandonado pola súa muller despois de telo humillado e menosprezado durante anos. O fillo queda canda o pai e xuntos intentan buscar unha solución a tan lamentable situación, que pasa pola posibilidade de marchar ás Américas a buscar mellor fortuna.

A idealización neste relato xa aparece proxectada no home co que marcha a muller, unha persoa forte, viril e cun carácter decidido, características todas elas que o rapaz quixera para o seu pai. Del di: "Si el meu pare fos un home de la fusta d'en Quim, no s'ho prendria pas tan a la pia (...). Però, és clar, si el pare fos com en Quim, la seva dona no l'hauria plantat..." (1995: 111).

Á súa vez, o pai é unha persoa pusilánime que sempre fala con nostalxia do pasado, de cando traballaba nos barcos, e que bota de menos eses tempos que xa non van volver: "Ai, si haguessis vist el Remedios..., allò sí que era un pailebot! Jo vaig treballar, però va ser l'últim..."” (1995: 109). Ademais, ten moi idealizado o seu amigo Tau:

Ah, però en Tau ja és diferent. Ell ha voltat la Ceca, la Meca i la Vall d'Andorra... Ell ha passat la mar grossa, ha estat a les Amèriques, $i$ fins hi té amics d'upa, forrats d'unces, allà pel Barranquillu i per les Matances..., què sé jo! $(1995: 109)^{8}$

Pero antes de abandonalo, a súa muller lémbralle o fracaso do amigo en América, un lugar onde é moi doado triunfar: "Però si tothom ho sap que per fer-se ric, allà només cal ajupir-se a collir la plata de terra..." $(1995: 110)$. Esta é unha imaxe das Américas que sabemos que tampouco é real e que vén completar un panorama familiar no que todos os membros da familia queren escapar da realidade hostil que os envolve.

Tras o abandono da muller, o pai pídelle axuda a ese amigo admirado. E el entrégalle unha carta de recomendación para un coñecido seu que pode ofrecerlles traballo na terra prometida. O pai e o fillo deciden vender a casa familiar e marchan na procura dese ideal

\footnotetext{
${ }^{3}$ Carlos Blanco Aguinaga (2006) fala da nostalxia do exiliado e marca unha data clave: a da primavera de antes da guerra, ese espazo temporal ao que todos os exiliados queren volver para seguir formando parte da historia do país.

${ }^{4}$ En galego: A cidade e o trópico. As traducións ao galego dos textos citados desta novela son miñas.

5 "A letra".

6 "Se o meu pai fora un home do estilo do Quim, non o tería tomado todo tan á tremenda (...). Pero, claro, se meu pai fora coma o Quim, a súa muller non o tivera plantado...".

7 "Ai, se viras o Remedios..., aquel si que era un pailebote! Eu traballei nel, pero foi o derradeiro...".

8 "Ah, pero o Tau xa é diferente. El recorreu a Ceca, a Meca e o val de Andorra... El pasou pola mar brava, estivo nas Américas e incluso ten uns amigos de olé..., forrados de onzas, aló polo Barranquillu e polas Matanzas... Que sei eu!".

9 "Pero se todo o mundo sabe que para facerse rico, aló, só hai que agacharse e coller a prata da terra...".
} 
que os saque do fastío e da humillación. Di o fillo: "Em sentia agitat per aquella decisió de deixar-ho tot, però m'agradava que no acabés de perdre la mica de respecte que el pare m'inspiraba encara i que ens n'anéssim lluny, ben lluny"10 (1995: 112).

A importancia desta carta vai ser vital para eles; representa unha sorte de salvoconduto que lles vai abrir as portas da liberdade:

Però no estic tranquil. Abocat a la borda, de sobte me n'aparto esgarrifat, amb les mans compulsivament estretes contra el pit. 'La carta!', em dic. La lletra de recomanació que porto damunt del cor... He imaginat que em podria caure al mar (...). Fins que la mà palpa la rigidesa dels dos sobres on l'he entaforada, no estic tranquil. El vell i jo, sense la carta, seríem com un vaixell sense campana i sense port d'arribada. $(1995: 115)^{11}$

O momento de enfrontar a realidade aparece deseguida ao chegar ao lugar recomendado, unha empresa que semella estar chea de actividade. Pero tras a aparencia de normalidade, espera un destino cruel. O empresario bota a rir e dilles:

Ja us he dit que era molt graciós... Tota aquesta activitat, tot aquest anar i venir, no és pas per al meu profit. Heu aparegut just a la darrera escena: assistiu a la liquidació judicial de tots els meus béns, a la darrera etapa de la venda en pública subhasta del negoci. Aquests homes s'emporten tot el que havia estat meu... Ja ho veieu: no queda res. (1995: 118-119) ${ }^{12}$
A decepción é total. A terra prometida non ten nada que ofrecer e os protagonistas vense en soidade fronte aos seus medos e sen recursos. Pero ao final do relato aparece a esperanza, porque o rapaz verá por fin a reacción do pai, que lle di ao empresario:

Però som aquí pel que calgui — seguiaencara tenim cinc dits a cada mà, refotre, i, si érem prou bons per venir a pidolar-te galeta a bord, bé ho hem de ser per dar-te un cop de mà. Pit i fora, Salichs. No estàs pas sol. Com més mar, més vela! Tornarem a començar... (1995: $119)^{13}$

Asistimos así ao espertar do carácter adormecido, á exploración dos recursos propios e á reconstrución da identidade perdida; e tamén á construción dunha nova vida á pesar das reviravoltas do destino.

Hai máis exemplos de personaxes, paisaxes e tempos idealizados na literatura do exilio. Só por mencionar algún máis, rescataremos unha obra de José Blanco Amor escrita en 1959. Duelo por la tierra perdida narra os derradeiros anos de vida dun escritor exiliado en Bos Aires que deixou en España muller e fillos, e que mantén unha relación máis de odio que de amor coa súa esposa actual, unha muller que xa fora idealizada no seu día: "Mi realidad era el más absoluto desamparo y tú viniste a poblarla de esperanza. Eras la mujer ideal, esa mujer que no existe pero que uno la transforma en ideal porque sí. Hay que retenerla y defenderla para salvarnos" (1963: 39).

10 "Sentíame axitado pola decisión de deixalo todo, pero gustábame non terlle perdido o pouco respecto que aínda me inspiraba o meu pai e que nos fóramos lonxe, moi lonxe".

11 "Pero non estou tranquilo. Asomado á borda, de súpeto apártome arrepiado, coas mans compulsivamente apertadas contra o peito. 'A carta!', dígome. A letra de recomendación que levo enriba do corazón... Teño imaxinado que me podería caer ao mar (...). Ata que a man palpa a rixidez dos dous sobres nos que a teño oculta, non estou tranquilo. O vello e máis eu, sen a carta, seríamos coma un barco sen campá e sen porto de chegada".

12 "Xa vos dixen que era moi gracioso... Toda esta actividade, este ir e vir, non é para o meu proveito. Aparecestes xusto na derradeira escena: estades asistindo á liquidación xudicial dos meus bens, á última etapa da venda en poxa pública do negocio. Estes homes levan todo o que fora meu... Xa o vedes: non queda nada".

13 "Pero estamos aquí para o que faga falta — continuaba—: aínda temos cinco dedos en cada man, carallo, e, se fomos o bastante bos como para vir suplicarche traballo a bordo, tamén o seremos para botarche unha man. Bota peito, Salichs. Non estás só. Canta máis mar, máis vela! Volveremos a comezar". 
De novo aparece a idea da salvación a través da invención dunha situación ideal, como víramos en $A$ fuxida. A mensaxe que se transmite neste caso é a de que a única forma de sobrevivir ao exilio é creando unha nova realidade que solape a que hai.

Pero deixar atrás un pasado non resolto ten consecuencias. E un día as vellas historias volven para axustar contas cos que as esqueceron, porque ante a falta de sinceridade interna, nin o pasado nin o presente poden proporcionar ao exiliado a reconciliación desexada. Así se reflicte nesta mesma obra, no momento en que os fillos do escritor lle escriben unha durísima carta para comunicarlle a morte da súa primeira muller:

Clara Lucía y yo, al firmar juntos estas líneas, no tenemos otro propósito que el de informar a Ud. de algunas novedades. El hecho de que la presente no lleve encabezamiento se debe a que ya nos olvidamos del tratamiento de padre que le dábamos.

Nuestra madre ha muerto el domingo pasado. Hacía años que estaba enferma, pero la mató el disgusto de saber que nos ha vendido Ud. todo y no conforme con eso que nos van a desalojar de la casa de Recoletos, en la que nacieron nuestros abuelos, nació usted y nacimos nosotros. Sus dos nietos (...) también nacieron aquí, pero ellos no saben que Ud. les vendió la casa. No saben que Ud. existe. (1963: 136)

Posteriormente saberemos que a recepción desta carta vaille traer consecuencias fatais.

Por último, mencionamos unha novela do escritor Mariano Tudela publicada en 1988 e titulada Amarga canción del recuerdo. A obra ofrécenos unha reconstrución de historias entrelazadas de varios exiliados, nun percorrido que nos leva por distintos lugares e momentos históricos desde a guerra ata a morte do ditador.

Unha destas historias é a de Cipriano Almudia, un exiliado en París que está moi orgulloso da súa filla e da vida que leva ela en Bos Aires. Sempre fala dela e das súas cartas, que recibe puntualmente. Pero axiña saberemos que se trata dunha realidade disfrazada, porque a filla, que ten un tumor cerebral, anticípanos o desenlace cando lle di ao seu home por que escribe as cartas a máquina, e non a man:
Es que sé que si todo esto no marcha bien mi padre no podría resistir mi ausencia. Se destrozaría... Te lo pido por lo que más quieras (...), deseo que si algo me ocurre sigas escribiendo a mi padre como si fuese yo. La firma te será fácil de imitar. (1988: 88)

Efectivamente, cando morre a filla, o marido continúa co labor de manter a ilusión do pai, que morrerá sen coñecer a verdade.

Outro dos fíos de Amarga canción del recuerdo lévanos á historia de Nicole e Abel. O rapaz, morto nunha emboscada durante os comezos da Segunda Guerra Mundial, quedou por sempre no corazón da rapaza, unha francesa que nunca se recuperou da perda. A aparición doutro home fai que ela intente recrear nel a historia rota do amor desaparecido, proxectando nesta nova relación as súas ilusións de felicidade e formando unha familia.

Pero Nicole sofre constantes depresións e sométese con frecuencia a tratamentos psiquiátricos, algo que chama a atención dos achegados ao seu home, Jacinto. Así e todo, o esposo pecha os ollos á realidade e xustifica o carácter ausente da súa muller recorrendo ao tópico da nacionalidade: "Lo que pasa es que Nicole no es tan expresiva como yo. La perfecta francesa, ¿no os dais cuenta? No quiere vertirse hacia fuera, mostrar demasiado sus sentimientos. ¡Ya la iréis conociendo!” (1988: 205).

Tras negar reiteradamente o carácter depresivo de Nicole, e despois do seu suicidio, Jacinto darase conta da súa cegueira:

La felicidad, creo que compartida, de aquella noche no me dejó ver los riesgos a que me exponía pidiéndole que se casara conmigo. Debí darme cuenta de algo que sucedió aquella noche y en lo que yo no quise pararme a pensar. Me abrazó y me colmó los oídos de palabras de ternura, pero cuando quiso llamarme por mi nombre fue como si acabase de padecer un escalofrío repentino... Parecía incapaz de decir $J a$ cinto en español, y aunque al final pronunció mi nombre, ahora comprendo, al cabo de los años, que aquel nombre no era el mío. Dijo Jacinto, pero Nicole quería decir... Abel. (1988: 211)

De novo, faise evidente a supremacía da realidade e aparece o recoñecemento daquilo 
que fora negado, malia que moitas veces, coma neste caso, esa aceptación chegue demasiado tarde.

\section{CONCLUSIÓNS}

Os textos citados son exemplos literarios que ben poderían representar casos reais. Mostran os intentos, en balde, de rescatar o pasado e de reparar - mediante a inventiva- as perdas ocasionadas polo exilio. Pero o "destempo" imposibilita ese rescate, tal e como afirma Claudio Guillén: "La recuperación del espacio es ilusoria. O imposible (...). La temporalidad moderna es lo que hace que el regreso del exiliado a su propio país sea tantas veces amargo, problemático, irreal" (2007: 88).

A restauración do pasado parece inalcanzable, sobre todo cando a ilusión converxe coa irrealidade. Ningún ideal é capaz de cambiar os feitos, e só a través da catarse final, que permite confrontar e liberar o trauma reprimido, os exiliados poden acadar un estado de paz dentro da ruptura. En caso contrario, estarán condenados a camiñar pola vida como seres divididos; e coa división da identidade chegará a debilitación da forza, a perda do rumbo e o abandono do propósito vital.

O futuro non nace da idealización nin da negación do presente. Nace da aceptación do pasado; da substitución de modelos de conduta que quedaron obsoletos; da superación de sentimentos alienantes; da unión cos valores propios e da formación doutros novos. Nace da reconciliación interna, cando en moitos casos a reconciliación co país non é factible.

Ese é o camiño da construción da identidade; un traxecto que deriva na reconstrución da propia vida e no compromiso de levar a mellor existencia posible. Así e todo, non se debe desbotar a relevancia da idealización no exilio, porque na súa cara máis amable tende pontes cara a esperanza. E a esperanza é parte necesaria do proceso de reclamación e adxudicación do lugar correspondente na memoria histórica e, por tanto, na historia da literatura universal.

\section{REFERENCIAS BIBLIOGRÁFICAS}

Blanco Aguinaga, Carlos (2006): "La primavera (perdida) y la historia", en Ensayos sobre la literatura del exilio español. México D.F.: El Colegio de México, pp. 73-89.

Blanco Amor, José (19632 [1959]): Duelo por la tierra perdida. Buenos Aires: Losada.

Ferran de Pol, Lluís (1995² [1956]): La ciutat i el tròpic. Prólogo de Jordi Castellanos. Barcelona: Curial.

GuILlÉn, Claudio (1995): El sol de los desterrados: literatura y exilio. Barcelona: Quaderns Crema.

(20072 [1988]): Múltiples moradas. Ensayo de literatura comparada. Barcelona: Tusquets.

Martínez OcA, Xosé Manuel (1983² [1980]): A fuxida. Vigo: Xerais.

Thompson, John (2009): As novelas da memoria. Vigo: Galaxia.

Tudela, Mariano (1988): Amarga canción del recuerdo. Barcelona: Anthropos.

VEIGA, Manuel (2004): O exiliado e a primavera. Vigo: Xerais. 